UCRL-ID-126454

\title{
Accelerated Stress Rupture Lifetime Assessment for Fiber Composites
}

\author{
S. E. Groves, S. J. DeTeresa, R.J. Sanchez,
} M. A. Zocher, R. M. Christensen

February 3, 1997

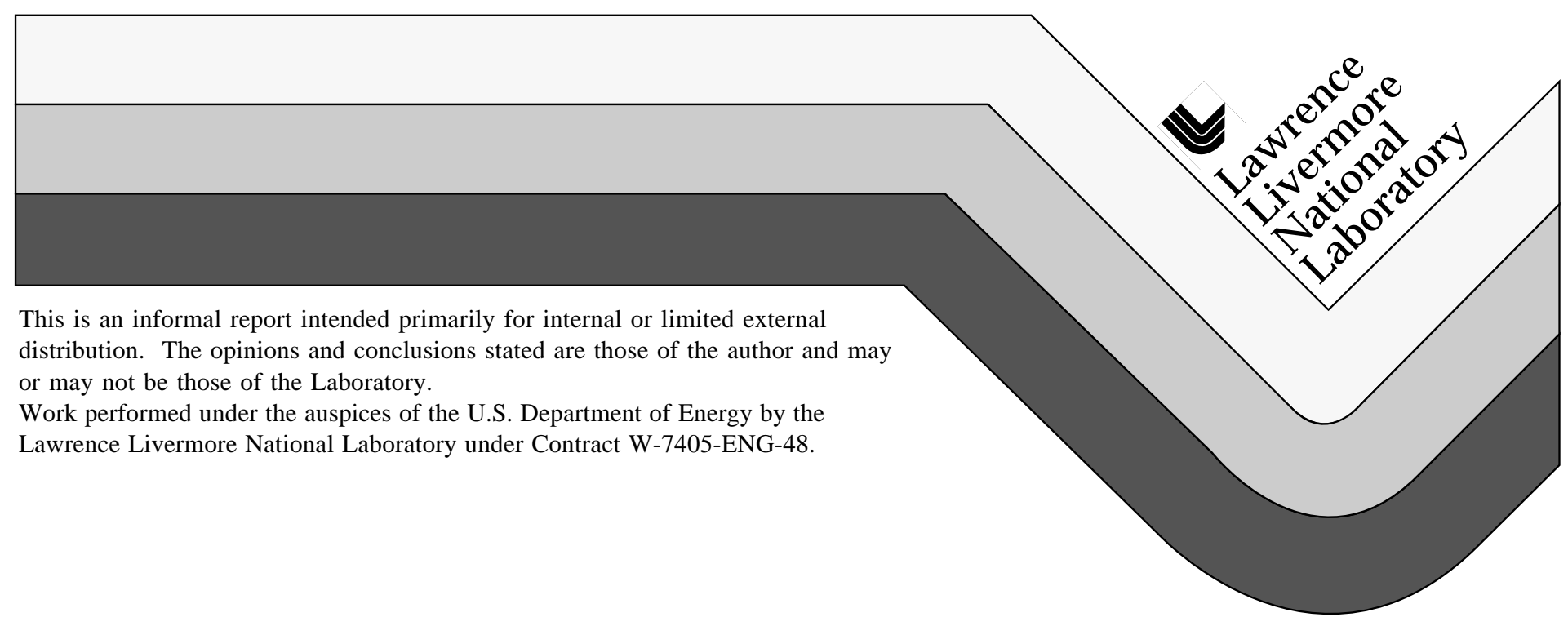




\section{DISCLAIMER}

This document was prepared as an account of work sponsored by an agency of the United States Government. Neither the United States Government nor the University of California nor any of their employees, makes any warranty, express or implied, or assumes any legal liability or responsibility for the accuracy, completeness, or usefulness of any information, apparatus, product, or process disclosed, or represents that its use would not infringe privately owned rights. Reference herein to any specific commercial product, process, or service by trade name, trademark, manufacturer, or otherwise, does not necessarily constitute or imply its endorsement, recommendation, or favoring by the United States Government or the University of California. The views and opinions of authors expressed herein do not necessarily state or reflect those of the United States Government or the University of California, and shall not be used for advertising or product endorsement purposes.

This report has been reproduced directly from the best available copy.

Available to DOE and DOE contractors from the Office of Scientific and Technical Information

P.O. Box 62, Oak Ridge, TN 37831

Prices available from (615) 576-8401, FTS 626-8401

Available to the public from the

National Technical Information Service

U.S. Department of Commerce 5285 Port Royal Rd.,

Springfield, VA 22161 


\title{
Accelerated Stress Rupture Lifetime Assessment for Fiber Composites*
}

\author{
Scott E. Groves, Steven J. DeTeresa \\ Roberto J. Sanchez, Marvin A. Zocher, and Richard M. Christensen \\ Mechanics of Materials Group \\ Manufacturing and Materials Engineering Division \\ Lawrence Livermore National Laboratory \\ Livermore, California
}

\begin{abstract}
The objective of this program was to develop a theoretical and experimental framework for predicting the stress rupture lifetime for fiber polymer composites based on short-term accelerated testing. This was originally a three year project but was terminated after the first year due to insufficient funding. The first year of this project focused mainly on developing and initiating the experimental portion of the project, which included stress rupture experiments and viscoelastic material characterization.
\end{abstract}

In principle, higher temperature, stress, and saturated environmental conditions are used to accelerate the stress rupture behavior. Two types of specimens were to be subjected to long-term and accelerated static tensile loading at various temperatures and loads in order to quantify both the fiber and matrix dominated failures.

In conjunction with this effort, we were to apply state-of-the-art analytical and experimental characterization techniques developed under a previous DOE/DP CRADA for capturing and tracking incipient degradation mechanisms associated with mechanical performance.

Focus of this technology was to increase our confidence to design, analyze, and build long-term composite structures such as flywheels and hydrogen gas storage vessels. Additional applications include: advanced conventional weapons, infrastructures, marine and offshore systems, and stockpile stewardship and surveillance. Capabilities developed under this project, though not completed or verified, are being applied to NIF, AVLIS, and SSMP programs. 


\section{Introduction}

Despite all of the advances in materials and characterization technologies over the last 20 years, long-term performance modeling remains an outstanding problem in the design of durable advanced composite structures. More often, composite materials are being applied in structures requiring 10 to 50+ years of service. One of the advantages with the newer, stronger carbon fibers, is that they are exhibiting significantly longer lifetimes (a major improvement for flywheels and pressure vessels). However, this creates experimental difficulties trying to generate a sufficient amount of stress rupture failure data in a manageable period of time (3-5 years) from which to assimilate and validate models. Therefore, in order to be able to predict long-term performance, we must develop an accelerated methodology.

The major differences in this project over the past efforts at LLNL to explore composite stress rupture were two-fold. First, focus was to be on accelerated material failure. Second, fundamental science-based degradation mechanisms and signatures were to be identified and tracked using a myriad of state-of-the-art chemical and physical analysis tools. Attempt would be made to correlate the degradation signatures with mechanical performance. This information would then provide for a science-based approach to develop a methodology for accelerated material testing. Chemical signatures would include molecular fingerprints and degradation byproducts (measured using techniques such FTIR, GC-MS, TMA, TGA, and NMR). Physical signatures would include free volume, weight loss, thermal properties, damage accumulation, attenuation, etc.

Earlier work at LLNL seemed to focus most of its efforts on statistical aspects of scatter in the failure data itself [1-3]. Some efforts were made at incorporating a chemical degradation mechanism [4].

This project leveraged the major accomplishments and facilities developed under an existing DOE/DP CRADA with Boeing Commercial Airplane Group on "Strength and Durability of Continuous Fiber Polymer Composites." A critical task of this program was to develop and establish the required techniques to generate, monitor, and verify that the acceleration methods (mechanical, chemical, physical) do not introduce artificial aging mechanisms. One such method, that has been partially developed under this CRADA with Physics and Space Technology, is the Positron Annihilation Spectroscopy system. This technique allows the user to rapidly probe materials for changes in free volume which accompanies physical aging and can be used to characterize critical materials for stockpile stewardship and surveillance. Another advanced technique, developed under this CRADA with Y-12, is the Barrel Ellipsoid Detector Diffuse Reflectance Fourier Transform Infrared Spectroscopy which allows surface chemistry changes to be measured in polymer and composite materials. Another technique, that could be utilized, is the atomic force microscopy system with nano-indentation (a capability which has been developed by Chemistry and Materials Science). This system can be used to measure hardness and potentially time-dependent force relaxation at the nano-meter scale in materials.

\section{Scope of Work}

In principal, higher temperature, stress, and saturated environmental conditions are used to accelerate the stress rupture behavior. A matrix of these tests is used to construct time-temperaturestress master curves via the superposition principal. The developing life prediction model will couple thermo-viscoelastic micromechanics, a kinetic fracture criterion [5], and statistics into LLNL's ORTHO3D algorithm (3-D orthotropic thermo-viscoelastic finite element code for composite materials) [6-9]. ORTHO3D is a material analysis code, as opposed to the structural analysis codes NIKE and DYNA. 
In this project, two types of test specimens were subjected to long-term and accelerated static tensile loading at various temperatures, loads, and environments in order to quantify both the fiber dominated and matrix dominated stress rupture failure. In addition to testing newer materials, where appropriate, we will utilize LLNL's existing database for S2-glass, Kevlar, and AS4 carbon fibers.

The state-of-the-art analytical and experimental characterization techniques, mentioned earlier, will be applied to capture incipient degradation mechanisms associated with mechanical performance.

Compared to the static strength, the lifetimes of a composite are statistically more widely scattered. Generally, this requires testing many specimens in order to obtain a statistically viable database. This is very time consuming, as-well-as costly.

\section{Task 1: Stress Rupture Experiments and Material Characterization}

The experimental data required for the life prediction are the viscoelastic material properties and the time-dependent strengths of the unidirectional composite. The viscoelastic properties include: the longitudinal and transverse creep functions, the shear creep function, and the major Poisson's ratio. The time dependent strengths are the tensile and compressive strengths in the fiber direction, the tensile and compressive strengths transverse to the fiber direction, and the shear strength.

In this project, only the fiber and matrix dominated tensile failure modes were investigated. These represent the critical failure modes for both flywheels and pressure vessels. All specimens will be subjected to constant, dead-weight, loading. The geometry and fiber orientation in these tests are shown in Figure 1.
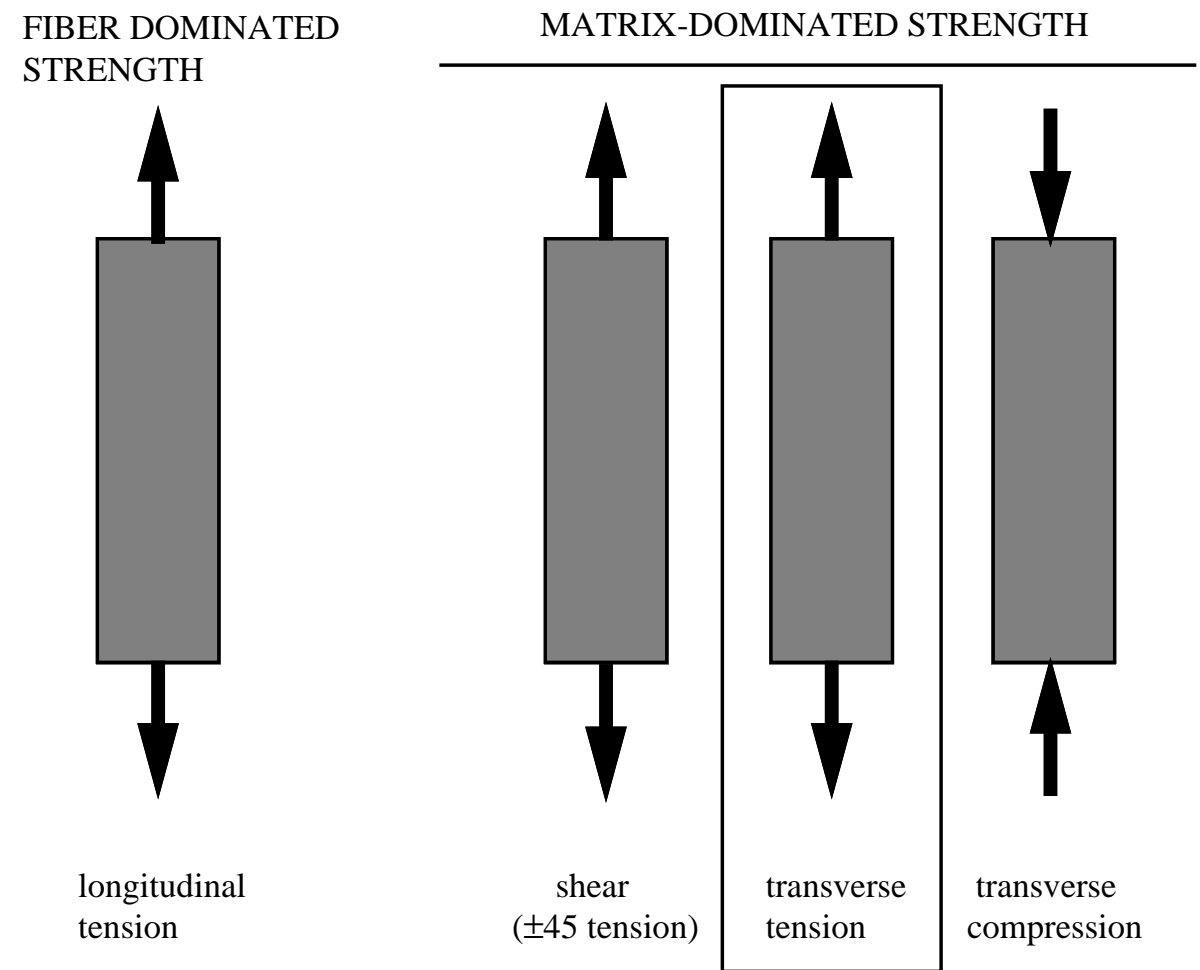

Figure 1. Specimen geometries and orientations. 


\section{Task 2: Proposed Theoretical Constitutive Equations}

This task centers on formulating a viscoelastic constitutive equation which recognizes the appropriate degradation mechanisms and a time-dependent failure criterion for transversely isotropic homogeneous materials. The assumption of equivalent homogeneity, while ignoring micromechanical features, is expected to lead to a constitutive equation that will capture the essential physics of the growing damage process leading to ultimate failure. The actual mechanisms of degradation, damage, and eventual failure in fiber composites are quite complicated. As evidence suggests from data for the Boeing CRADA program, accurate lifetime performance modeling must also include the effects of chemical and physical aging on the stress rupture lifetimes. Once this homogenized constitutive and time dependent failure criterion is established, it will be integrated into an ORTHO3D/NIKE3D combination for structural lifetime modeling.

Two approaches were utilized in our modeling efforts:

Our first approach at lifetime modeling utilized the kinetic fracture theory [5]. This theory has two primary components. First, generalized fracture mechanics relationships for crack growth are modified to include time and rate dependent mechanisms for modeling the failure process. Second, a Weibull statistical distribution is applied to the intrinsic static strengths with regard to the crack growth parameters to develop a corresponding Weibull lifetime distribution.

An essential part of this effort is to deconvolute the effects of chemical and physical aging on the growth of the failure processes. This will involve both experimental and numerical decoupling. When applying time-temperature-stress superposition relations, the different degradation methods are assumed to be accounted for via individual time shift parameters. Within the framework of the kinetic fracture theory, different time constants would be introduced for each trackable (and identifiable) degradation mechanism.

Our second approach at lifetime modeling utilized ORTHO3D, our composite material analysis code. In this approach, a localized volume of interest (fiber, matrix, and interface) is modeled using thermo-viscoelastic three-dimensional finite elements. Numerical/geometrical representations of actual mechanisms of degradation and damage can be simulated in the local volume. These can include: constitutive degradation in the matrix due to chemical and physical aging, stress relaxation (apparent aging) at the interface due to residual stresses, interface debonding, and matrix cracking, all of which can be time dependent. The effect of each on the local volume response will be calculated and used to determine an equivalent homogenized material response for the local volume (i.e., an homogenized constitutive response).

Absent from this approach, with regards to life prediction, are the corresponding growth laws (kinetics) for each of the degradation mechanisms. The local volume modeling approach will enalbe numerical decoupling of the associated degradation mechanisms. The homogenized kinetic fracture theory, in itself, is a growth law model. 


\section{Results}

During the first year of this project we were able to complete the intrinsic stress rupture measurements for uniaxial rods at $23^{\circ} \mathrm{C}$ and transverse tensile strengths at 23,80 , and $120^{\circ} \mathrm{C}$ on our T1000/1908 carbon/epoxy material system (60\% carbon fiber $/ 40 \%$ matrix). Most of our effort focused on initiating long term $23^{\circ} \mathrm{C}$ testing on uniaxial and transverse specimens. At one time we had 61 creep rupture stations under load. A summary of these test results are shown in Figures 2-4. A photograph of the long term stress rupture facility is shown in Figure 5.

Figure 2 shows the results for the uniaxial tension stress rupture measurements for the T1000 material system at $23^{\circ} \mathrm{C}$. (This represents the fiber dominated mode.) The intrinsic data is shown at the initial time of 0.001 hours. The average tensile strength for this material system is $545 \mathrm{ksi}$. This is over $200 \mathrm{ksi}$ stronger than any of the previous fiber composite systems tested at LLNL (kevlar, glass, and carbon). The open data circles at this point reveals the inherent statistical scatter in the data. The uniaxial test specimen is comprised of a single $12 \mathrm{k}(12,000$ filament) tow cured in the form of a cylindrical rod, approximately 0.026 " in diameter. In the past stress rupture was conducted using specimens in the form of a uniaxial flat ribbon. Gripping of the high strength T1000 ribbons proved to be highly difficult. To much care was required to prevent grip failures and the results were highly scattered. After considerable effort and testing, the final grip design for the uniaxial rods consisted of pressing a straight hardened steel rod $\left(\sim 0.025^{\prime \prime}\right.$ in diameter) into two matching halves of 3.0" long x 1.0" wide aluminum pieces bolted together along each side. Primary gripping was obtained by bonding the rods into the recessed hole in the aluminum grip halves using Hysol EA 9396 ( a two part, room temperature cure system). For this application accelerated curing for 1 hour at $150^{\circ} \mathrm{F}$ was used. Overall this technique has proven to be very robust. After over 20,000 hours of testing, only two specimens have slipped due to bond failure.

Quite frankly, these results have been very surprising. We did not expect the T1000 rods to exhibit the extreme longevity as shown in Figure 2. The enclosed black dots indicate that specimens are still under load and the oval with the number inside indicate how many specimens at this stress level are still under load. Quick look at the axis scaling shows that almost all of our specimens have been aging at stress levels of $85 \%$ ultimate and higher.

A comparison of stress rupture data for Kevlar 49, $\mathrm{S}_{2}$ glass, and AS4 carbon fiber to our present T1000 carbon fiber composite material system is shown in Figure 3. The major point of interest here is the fact that, for the earlier material systems, the $50 \%$ failure curve (line drawn through failure data such that at least $50 \%$ of the test specimens at this stress level have failed) was essentially completed by the 10,000 hour mark for stresses between 60\%-90\% static ultimate strength. In our current effort with the new T1000 carbon fiber system, we have not yet approached any sign of the $50 \%$ mark, even at $90 \%$ ultimate. The $90 \%$ ultimate stress rupture experiments on T1000 is exhibiting at least a five fold increase in log time life.

Figure 4 shows the results for the transverse tensile stress rupture measurements at $23^{\circ} \mathrm{C}$. (This represents the matrix dominated failure mode.) Again the intrinsic failure strength is shown at the initial time of 0.001 hours. The average transverse tensile strength is 8732 psi. This test specimen is significantly different in geometry than the uniaxial test specimen. It is $1.0^{\prime \prime}$ wide, 0.09 " thick, and 10.0" long. The transverse tensile strength is essentially limited by the performance of the matrix itself. This type of geometry coupled with the poor performance of the matrix itself produces very difficult gripping problems. Though we spent considerable effort to minimize gripping problems, we were never able to completely eliminate grip related failures. The grip for this test specimen was a friction grip consisting of two bolted halves of aluminum. At relatively high stress rupture values we experienced numerous premature grip failures. These results are represented in Figure 4 by the diamond symbols. When performing short term tests such as our 
intrinsic measurements, specialized pressure controlled hydraulic grips are normally used to minimize grip related failures. Because of the number of tests required to generate a statistically valid stress rupture data base, it would be cost-prohibited to use this type of grip.

The results obtained from the long term transverse tensile stress rupture experiments are just as surprising as the unaxial results. Four specimens are still under load at 7500 psi (85\% ultimate). These samples are at stresses within the scatter of the intrinsic measurements.

Figures 2 and 4 represent the core of this project. It was hoped they would provide the means to validate our planned efforts in accelerated stress rupture. The obvious dilemma so far is the lack of failures occurring during the life of this proposal. This nevertheless emphasizes the need for an accelerated testing methodology. Generally the first step in accelerated aging of polymers is to apply temperature in the presence of load.

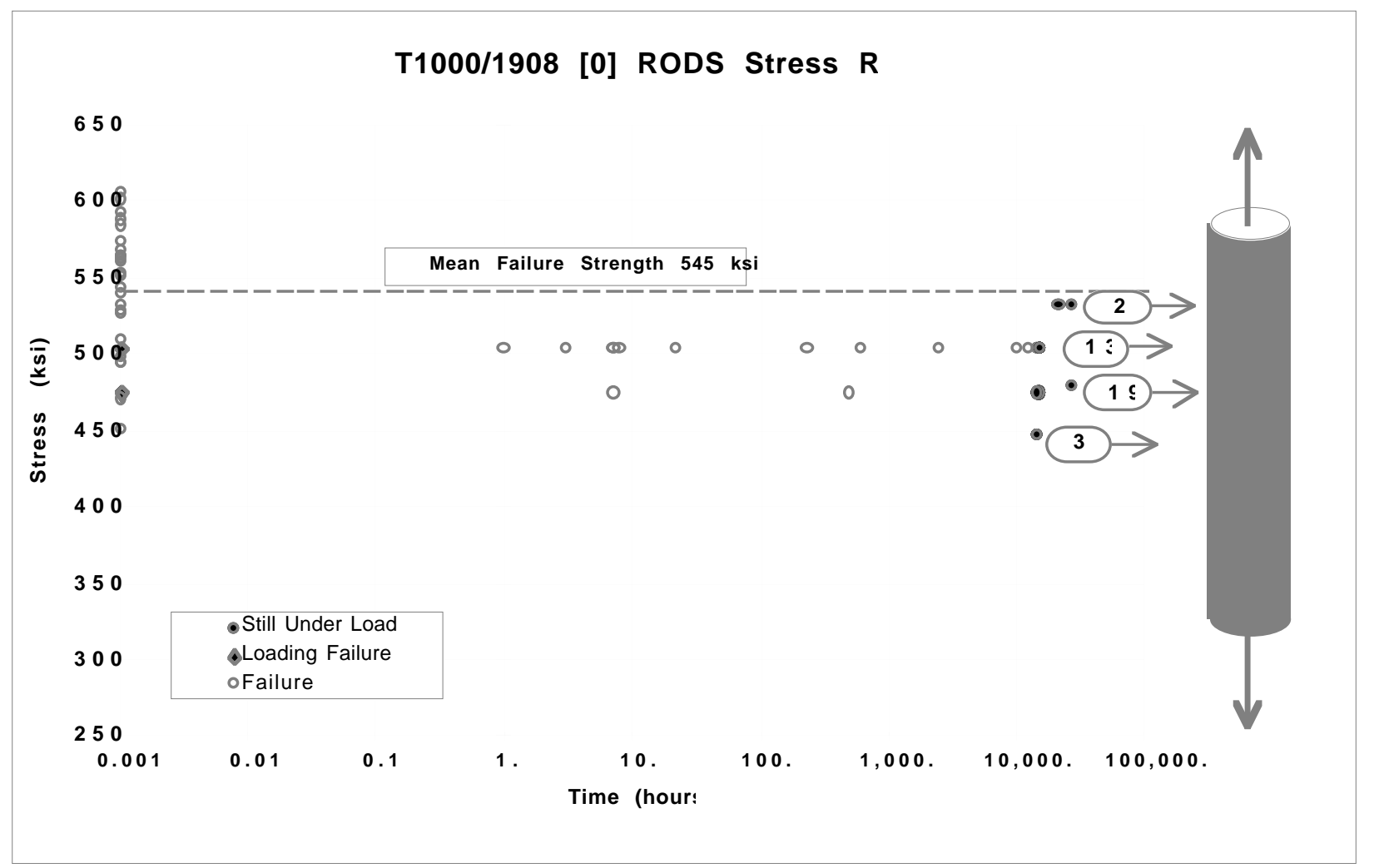

Figure 2. Stress rupture history for T1000/1908 carbon fiber uniaxial tension rods. 
T1000/1908 [0] RODS Stress R

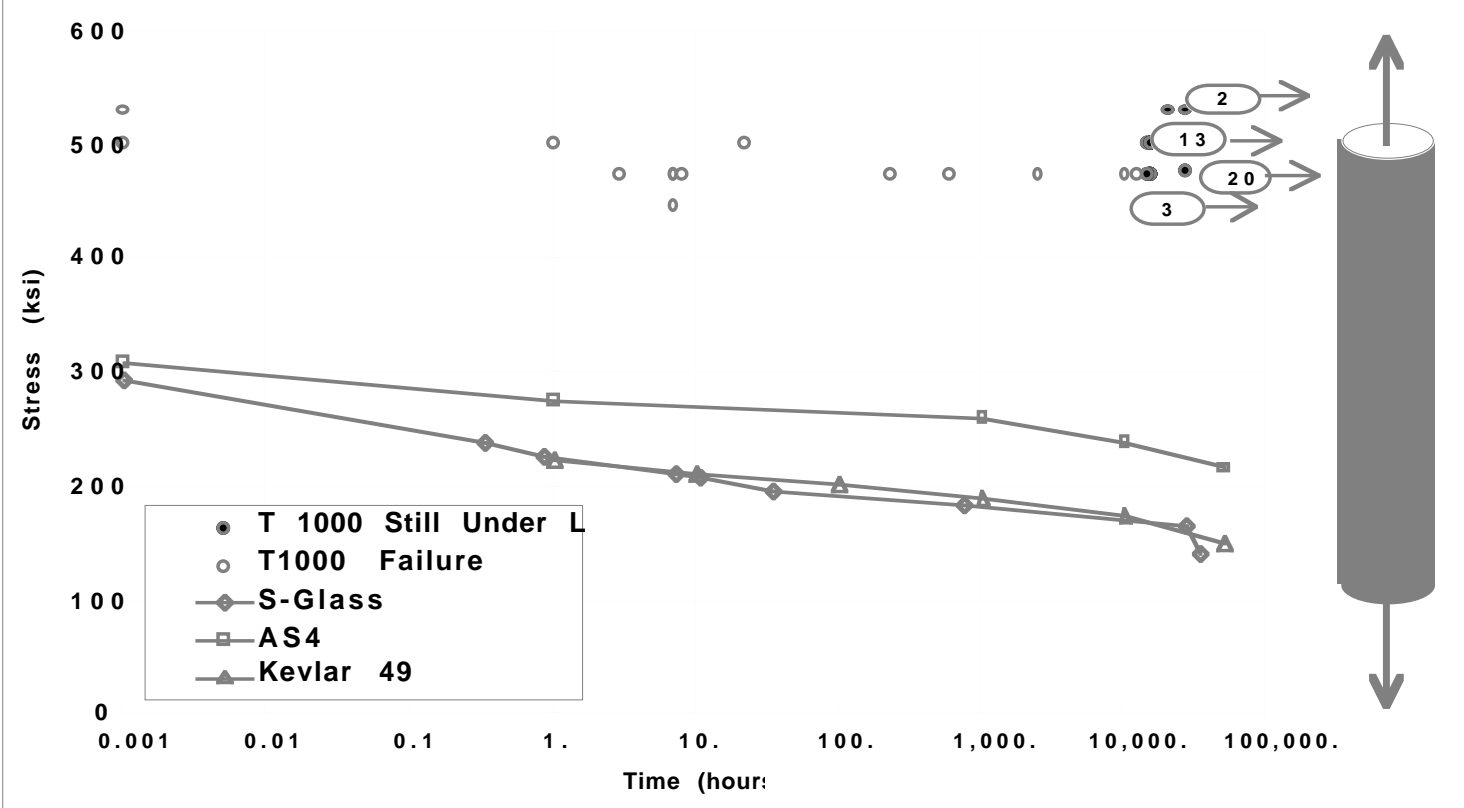

Figure 3. Comparison of mean $(50 \%)$ stress rupture failure history for LLNL fiber composite material systems.

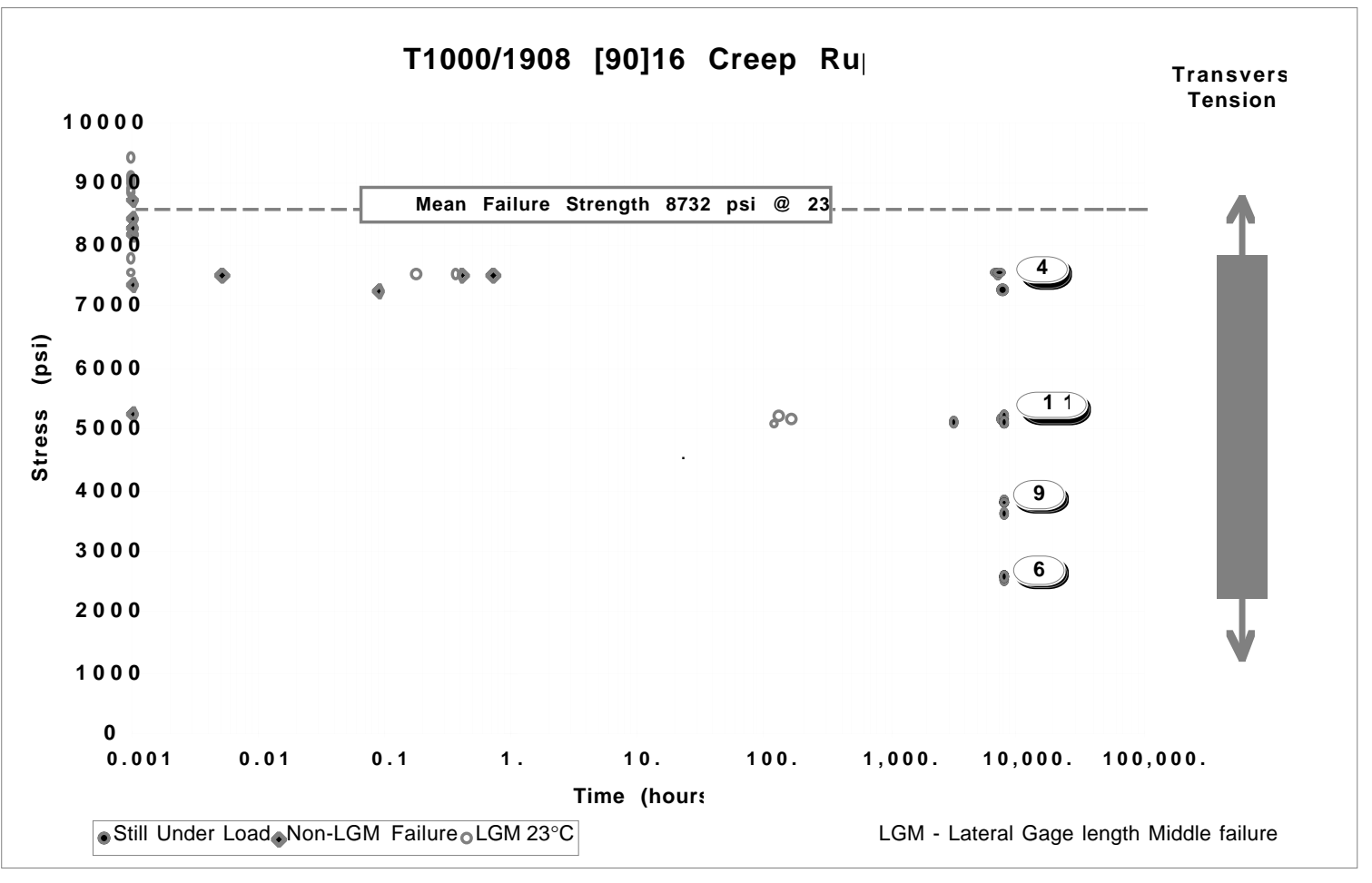

Figure 4. Stress rupture history for T1000/1908 carbon fiber transverse tensile specimens. Matrix dominated failure at $23^{\circ} \mathrm{C}$. 


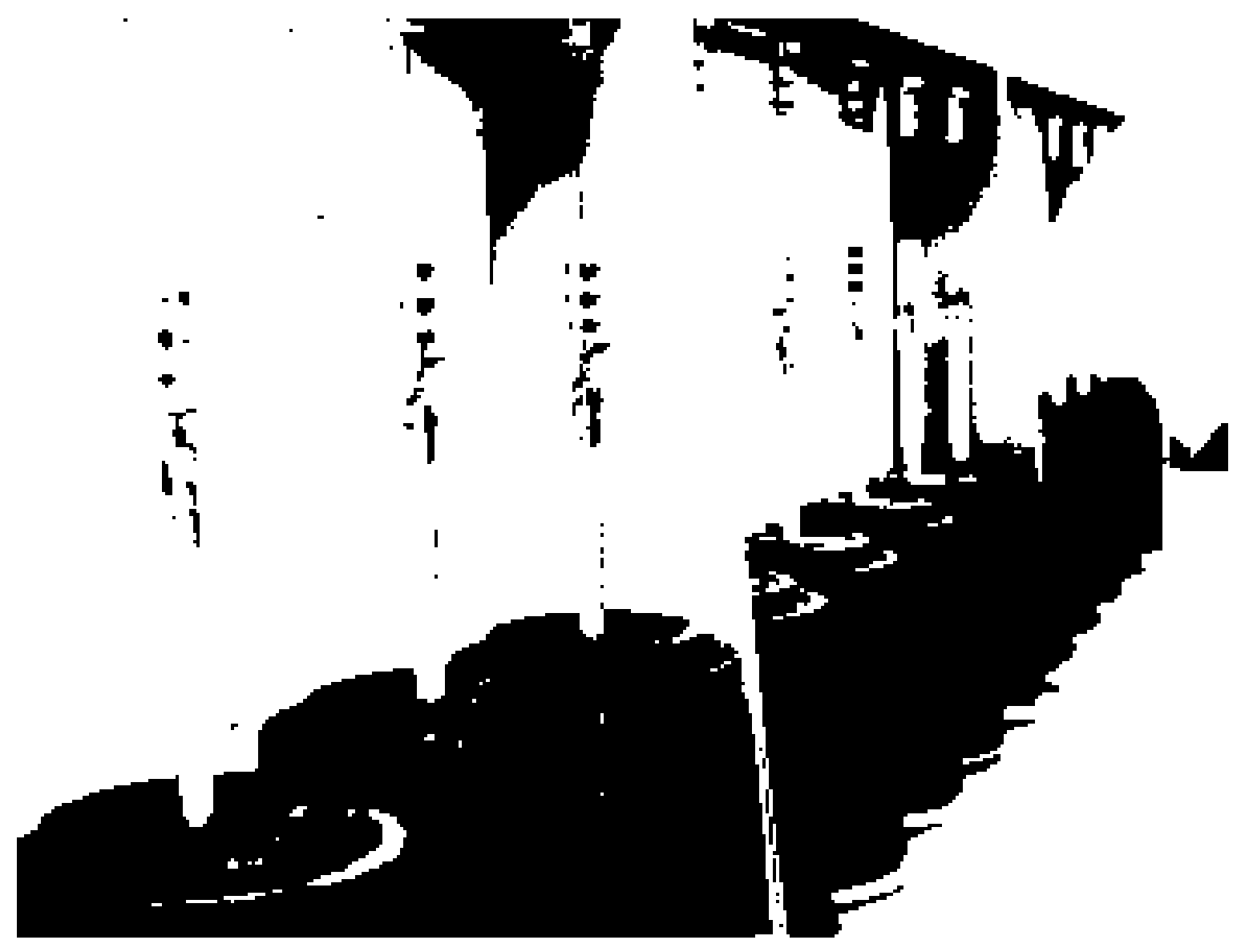

Figure 5. Long term stress rupture facility.

\section{Accelerated Testing: Various Possibilities}

Our first and primary method of accelerated stress rupture utilized higher temperatures. First, one must determine the intrinsic strength of the material as a function of temperature. We started with the most sensitive material mode, the transverse matrix dominated mode. Results are shown in Figure 6. One can interpret this result in various ways. First of all, it defines the available accelerated aging space. Anywhere along this curve would correspond to a " 0 " lifetime. Life is only possible to the left of this curve. For any given stress level at room temperature, this result would correspond to the upper bound stress levels available for temperature acceleration.

\section{Acceleration Method}

Is it possible to determine an equivalency in time between higher temperatures / lower stresses to lower temperatures / higher stresses? Does time-temperature-stress superposition hold? If so, can we generate a series of failure maps at temperatures above $23^{\circ} \mathrm{C}$ and in theory shift these curves to the right on our log scale to simulate longer aging times for $23^{\circ} \mathrm{C}$ ? Proceeding along these lines, we initiated a stress rupture study at $120^{\circ} \mathrm{C}$ on the transverse specimens using our 10-station atmospheric thermal chamber, to be followed by an $80^{\circ} \mathrm{C}$ study. The results from this study are shown in Figure 7. Stress ratios normalized to the respective temperature were chosen to be similar to those for the $23^{\circ} \mathrm{C}$ long term tests. In hindsight, this may have been a mistake. Only a 
few samples failed during the remaining time in the project and they were not considered to be legitimate gage failures. Gripping of our test specimen at higher temperatures proved to be a very difficult task. As with the $23^{\circ} \mathrm{C}$ test, the lower relative stress levels at $120^{\circ} \mathrm{C}$ showed signs of long lifetimes.

At this time we simply do not have enough data points to make a judgment. Higher temperature tests need to be performed. Another broad interpretation of this result is that for a given normalized failure stress level per temperature, the material would experience the same lifetime independent of temperature. If this result did indeed occur, would it imply that the same aging mechanisms are occurring? And if so, it also probably means that for this particular material chemical aging is a secondary effect.

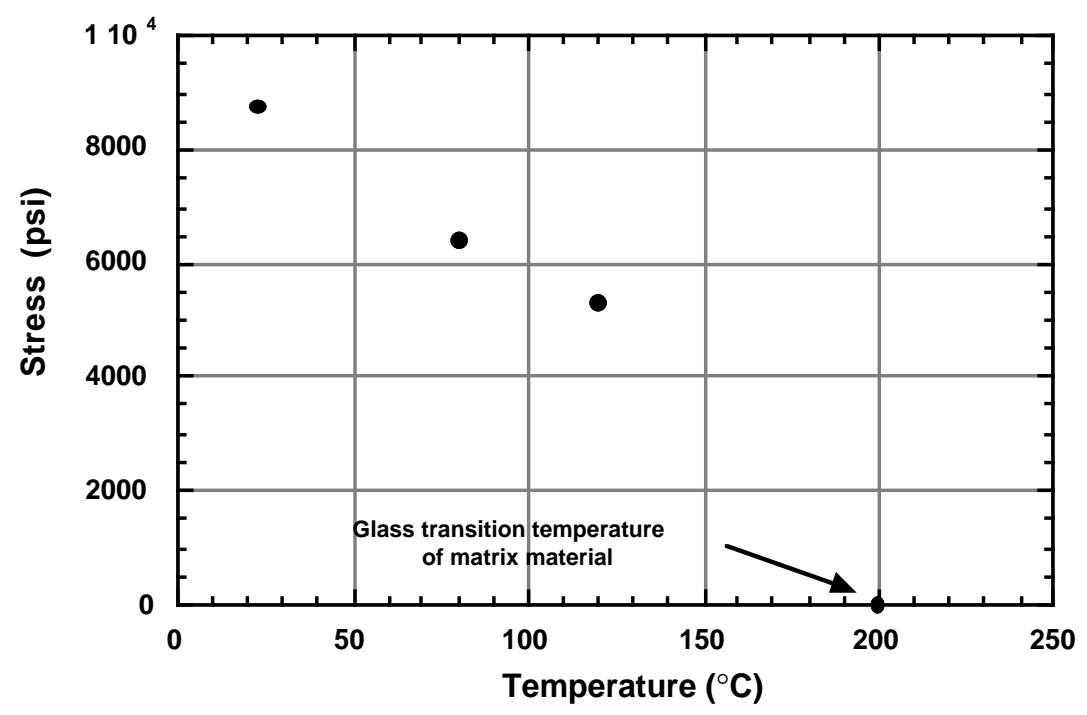

Figure 6. Temperature dependent intrinsic transverse tensile strength of the T1000/1908 material system. 


\section{T1000/1908 [90]16 Creep Ru|}

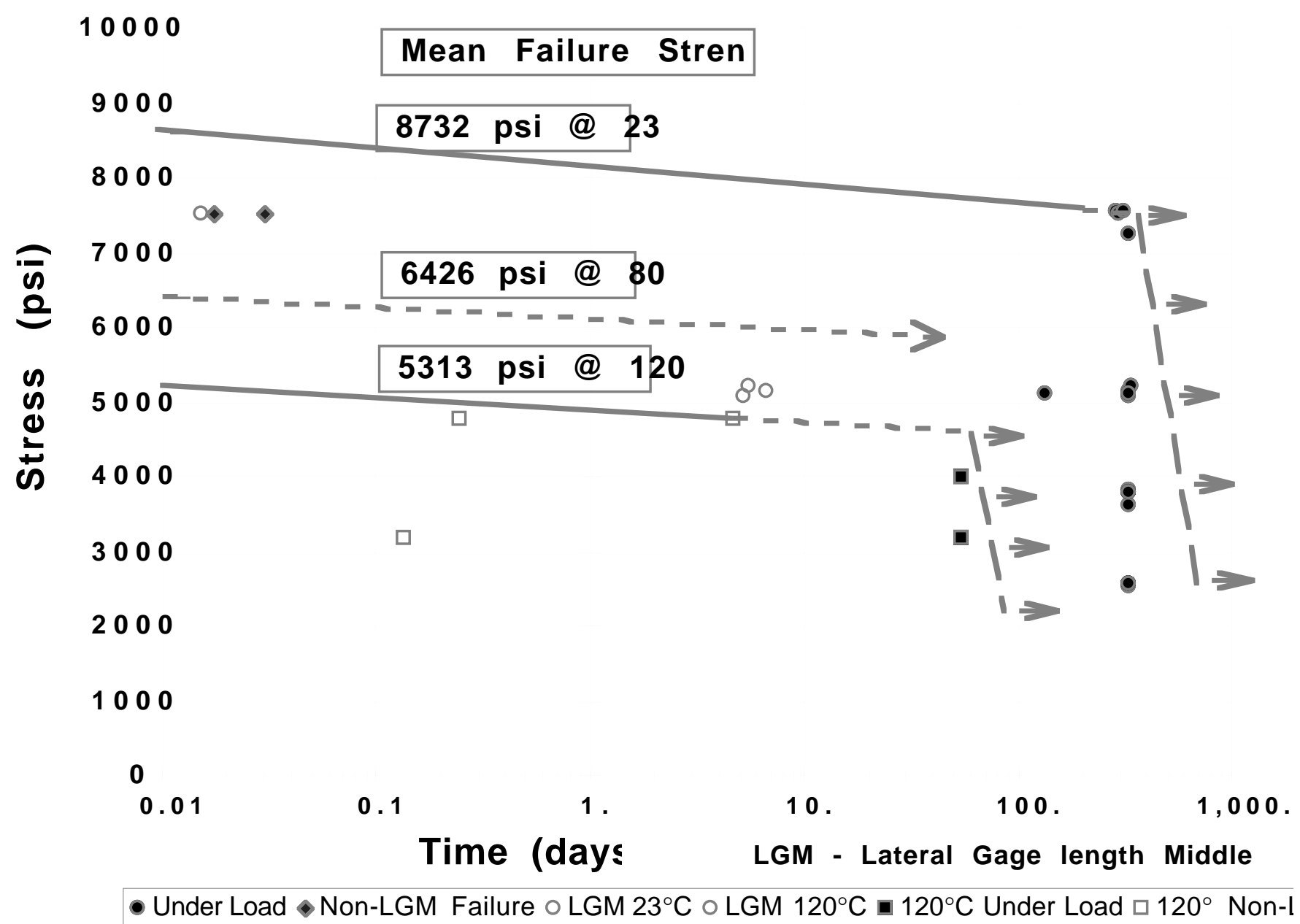

Figure 7. Stress rupture history for T1000/1908 carbon fiber transverse tensile specimens. Matrix dominated failure at $120^{\circ} \mathrm{C}$. 


\section{Another Acceleration Method}

This method is based on the concept that the intrinsic failure strength curve corresponds to 0lifetime $\left(\mathrm{t}_{0}\right)$, see Figure 8 . For any given stress level along this curve, reducing temperature would obviously lead to increasing life.

For example, at $100^{\circ} \mathrm{C}$, the maximum stress level is 6000 psi. This value has essentially 0 lifetime. Based on information from Figure 3 and the $23^{\circ} \mathrm{C}$ results, this stress level could easily have a life in excess of 10,000 hours, but we don't know exactly because we have no real-time failure data yet. The next step would be to conduct a series of tests at temperatures between $100^{\circ} \mathrm{C}$ and $23^{\circ} \mathrm{C}$ - focusing more towards $100^{\circ} \mathrm{C}$, since these accelerated tests would take less time to complete. Extrapolation of at least three temperature levels would allow us to estimate the life at $23^{\circ} \mathrm{C}$.

Basic assumption with this particular method is that significant chemical aging is not taking place and the primary mechanisms are mechanical in form (fracture, creep, debond).

The beauty of this approach is that in a relatively short period of time, the experimenter could develop a stress / temperature lifetime equation. The limitation is that equation is only valid for one stress value. However, by choosing a range of stresses, one could then generate a multistress valued time-temperature lifetime equation.

In the absence of chemical aging, these tests should be performed under actual operating conditions.

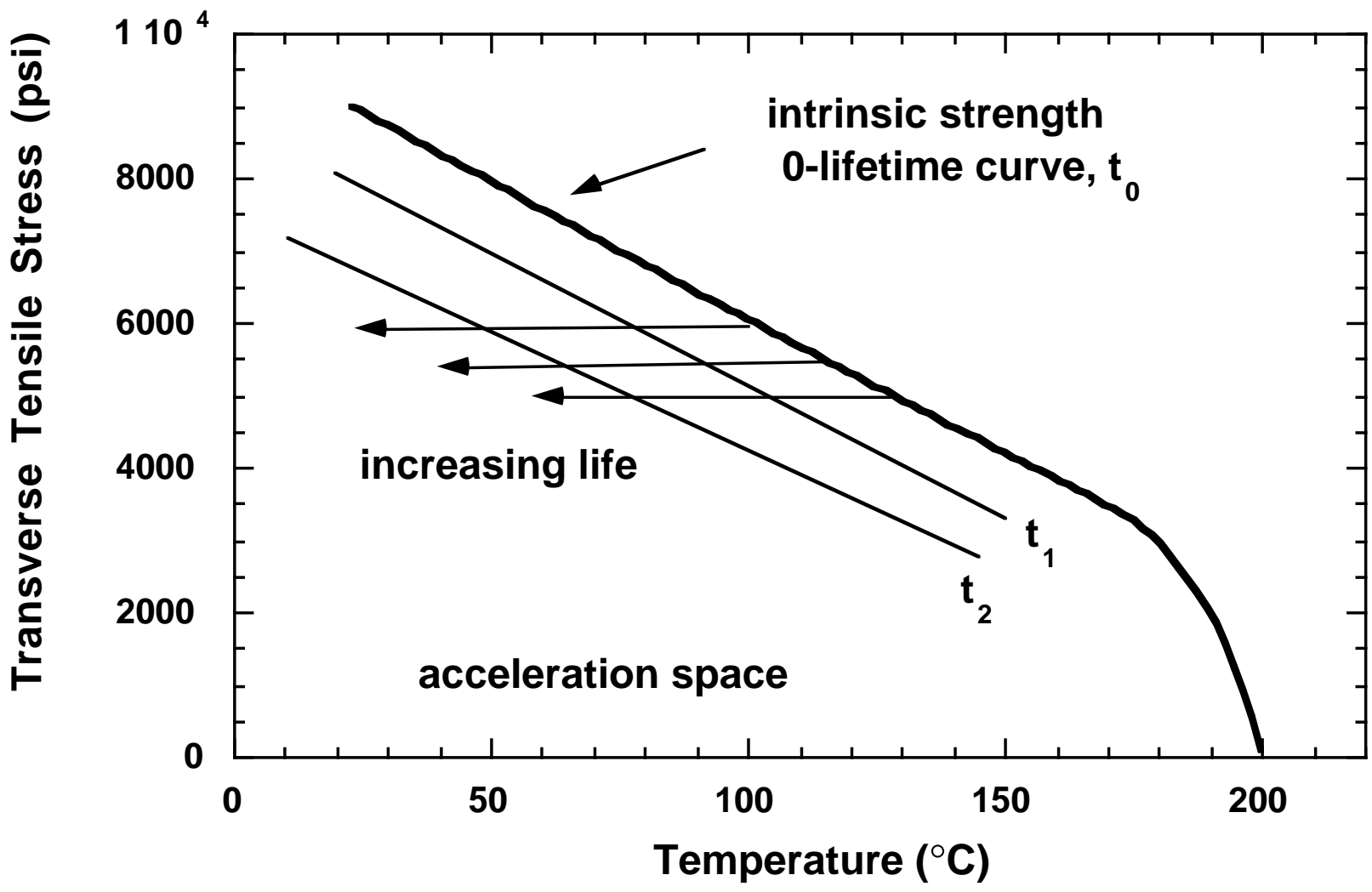

Figure 8. Domain of stress/temperature acceleration. Artificial data based on intuitive fit of data shown in Figure 5. 


\section{Accelerated Thermal Chemical Aging}

The effects of chemical aging on stress lifetimes is a natural extension of the method discussed in part 2. This task represents a second level of subdivision in an experimental test matrix. Accelerated chemical aging is performed by conducting a series of tests in low to saturated chemical conditions. To chemically accelerate a single stress level including temperature as well requires an extensive matrix of tests (even varying only one chemical event). To map out multiple stress levels temperatures, and chemistries can get to be rather extensive, but possible.

The accelerated thermal chemical creep rupture facility is shown in Figure 9. This system was designed to allow thermal stress rupture testing in the presence of controled ratios of oxygen / argon up to $80 / 20 \%$ conditions.

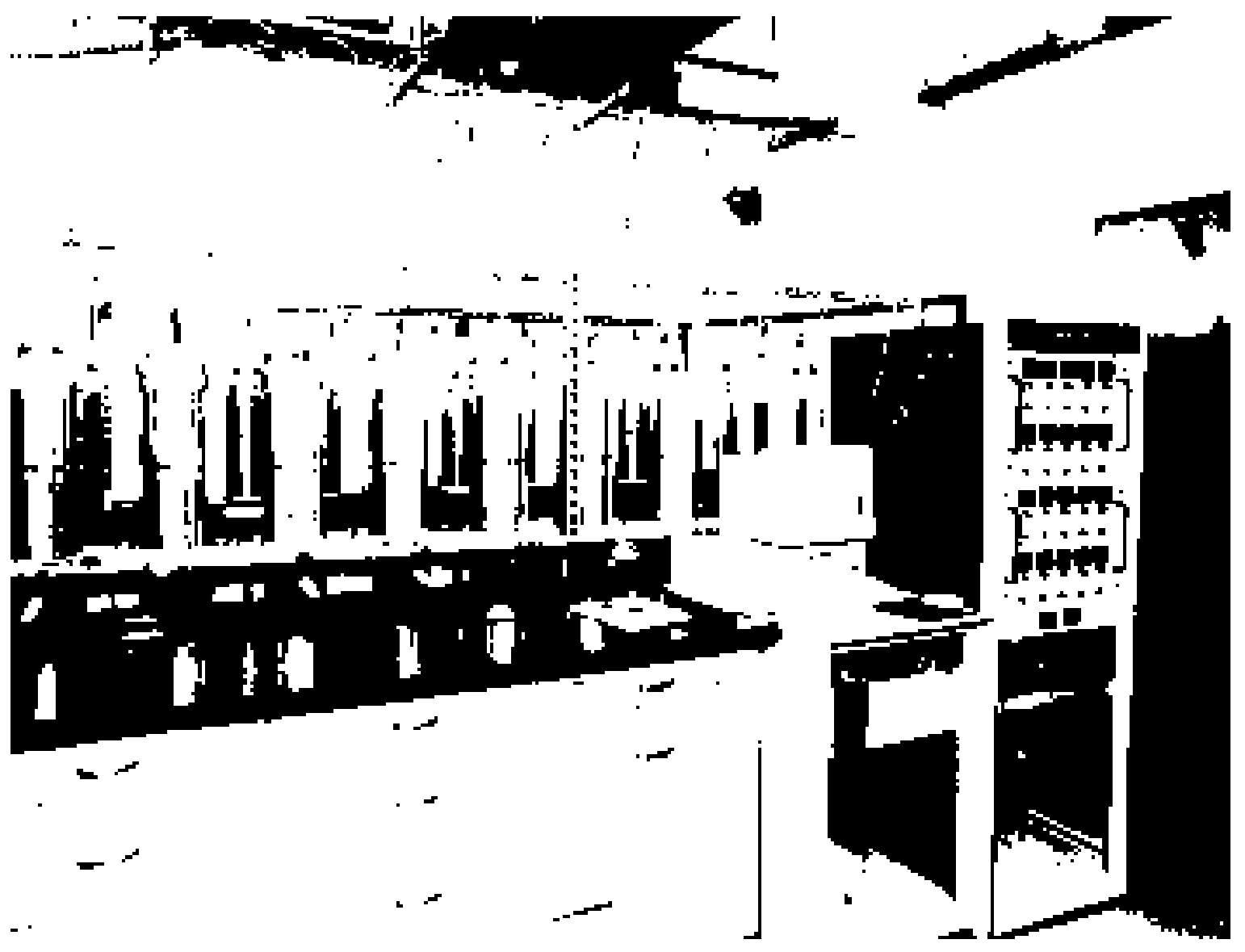

Figure 9. Accelerated thermal chemical aging facility. 


\section{Summary}

Our objective was to develop an accelerated methodology for predicting the stress rupture lifetimes for fiber reinforced composite materials. Though not completed this effort yielded significant experimental data on the T1000/1908 material system as well as improvements to our material analysis code "ORTHO3D" and an extensive experimental aging facility.

The real-time data generated on the uniaxial rods reveals that significantly greater lifetimes at higher stress levels are possible with this new material when compared to the literature data. This would be an advantage for this material when used in composite flywheels and gas storage systems. The real-time data generated on the $90^{\circ}$ transverse tensile specimens represents some of the most significant data generated of its kind to date. A limited amount of high temperature accelerated aging on the transverse tensile specimen was initiated at $80^{\circ} \mathrm{C}$ and $120^{\circ} \mathrm{C}$.

Essentially two types of stress/temperature acceleration methods were discussed along with one chemical acceleration method. The first being equated to a time-temperature-stress equivalency. The second method was based on the concept that the intrinsic failure strength curve corresponds to 0-lifetime. Given the short time that an experimental mechanician usually gets to characterize a material, the second method would be chosen for accelerating the stress rupture failure. However, a combination of all three methods must be imposed if one seeks a more robust accelerated methodology. Especially, one with the potential for finding out whether the material possesses any unusual failure mechanisms over extremely long times.

Had the project continued with the generation of the real-time and accelerated experimental testing, chemical/physical tracking analysis would have been initiated. This information is paramount to verifying acceleration mechanisms and would then be coupled to mechanical performance. The developing life prediction model would couple thermo-viscoelastic micromechanics and a kinetic fracture criterion into our 3-D orthotropic thermoviscoelastic finite element code, ORTHO3D.

Though certainly not verified by any means, we now at least have a recipe and facility for accelerating the stress induced failure of any organic material system and in most cases metals as well. In fact, we are presently applying these methodologies to several LLNL programs (Enhanced Surveillance, National Ignition Facility, and DOD Conventional Weapons).

\section{References}

1. Penn, L., "Stress Rupture Data for Kevlar 49 Epoxy Strands," UCID 17738, Lawrence Livermore National Laboratory Report, March 1978.

2. Glaser, R.E., Moore, R.L., and Chiao, T.T., "Life Estimation of an S/Glass Epoxy Composite Under Sustained Loading," Composites Technology Review, volume and date unknown.

3. Glaser, R.E., Moore, R.L., and Chiao, T.T., "Life Estimation of Aramid/Epoxy Composites Under Sustained Tension," Composites Technology Review, October 1993, also UCRL 89984.

4. Christensen, R.M., "Interactive Mechanical and Chemical Degradation in Organic Material," International J. of Solids and Structures, Vol 20, No. 8, 1984.

5. Christensen, R.M. and Glaser, R.E., "The Application of Kinetic Fracture Mechanics to Life Prediction for Polymeric Materials," Journal of Applied Mechanics, March 1985, Vol. 52. 
6. Zocher, M.A., Allen, D.H., and Groves, S.E., "A Three Dimensional Finite Element Formulation for Thermoviscoelastic Orthotropic Media," UCRL-JC-122524, submitted to International Journal for Numerical Methods in Engineering.

7. Zocher, M.A., Allen, D.H., and Groves, S.E., "Analysis of the Effects of Matrix Cracking in a Viscoelastic Composite at Elevated Temperature," Proceedings of the American Society of Composites, (9th Technical Conference), Technomic Publ., 1994, pp. 442-449.

8. Allen, D.H., Zocher, M.A., and Groves, S.E., "Apparent Physical Aging of Polymeric Composites," Innovative Processing and Characterization of Composite Materials (Proceedings, ASME Winter Annual Meeting, Nov 1995), Gibson, R.F., Chou, T.W., and Raju, P.K., eds., ASME Press, pp. 353-360.

9. Zocher, M.A., "A Thermoviscoelastic Finite Element Formulation for the Analysis of Composites," Ph.D. Dissertation, Texas A\&M University, College Station, TX, Aug. 1995. 


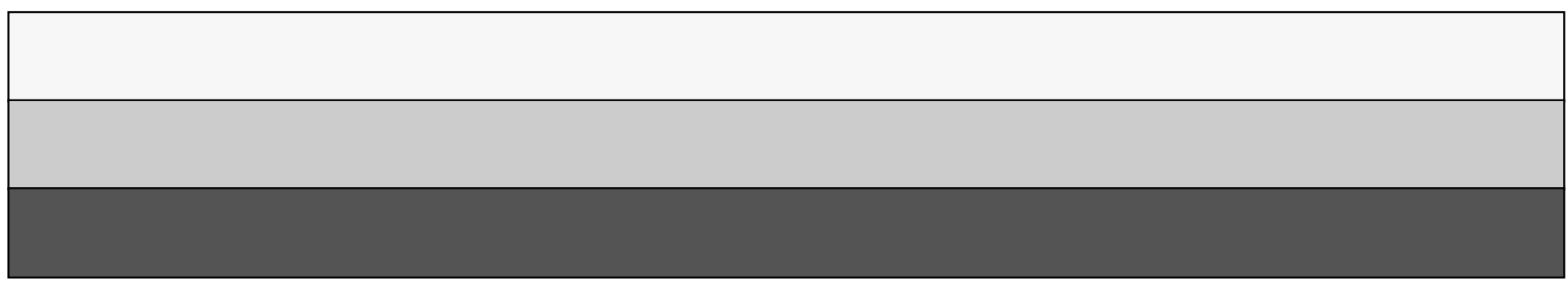

